\title{
The relationship between motor abilities and quality of life in children with severe multiple disabilities
}

Citation for published version (APA):

Mensch, S. M., Echteld, M. A., Lemmens, R., Oppewal, A., Evenhuis, H. M., \& Rameckers, E. A. A. (2019). The relationship between motor abilities and quality of life in children with severe multiple disabilities. Journal of Intellectual Disability Research, 63(2), 100-112. https://doi.org/10.1111/jir.12546

Document status and date:

Published: 01/02/2019

DOI:

10.1111/jir.12546

Document Version:

Publisher's PDF, also known as Version of record

Document license:

Taverne

Please check the document version of this publication:

- A submitted manuscript is the version of the article upon submission and before peer-review. There can be important differences between the submitted version and the official published version of record.

People interested in the research are advised to contact the author for the final version of the publication, or visit the DOI to the publisher's website.

- The final author version and the galley proof are versions of the publication after peer review.

- The final published version features the final layout of the paper including the volume, issue and page numbers.

Link to publication

\footnotetext{
General rights rights.

- You may freely distribute the URL identifying the publication in the public portal. please follow below link for the End User Agreement:

www.umlib.nl/taverne-license

Take down policy

If you believe that this document breaches copyright please contact us at:

repository@maastrichtuniversity.nl

providing details and we will investigate your claim.
}

Copyright and moral rights for the publications made accessible in the public portal are retained by the authors and/or other copyright owners and it is a condition of accessing publications that users recognise and abide by the legal requirements associated with these

- Users may download and print one copy of any publication from the public portal for the purpose of private study or research.

- You may not further distribute the material or use it for any profit-making activity or commercial gain

If the publication is distributed under the terms of Article $25 \mathrm{fa}$ of the Dutch Copyright Act, indicated by the "Taverne" license above, 


\title{
The relationship between motor abilities and quality of life in children with severe multiple disabilities
}

\author{
S. M. Mensch, ${ }^{1,2}$ (D) M. A. Echteld, ${ }^{4,5}$ R. Lemmens, ${ }^{6}$ A. Oppewal, ' (D) H. M. Evenhuis' \\ \& E. A. A. Rameckers ${ }^{3,7,8}$ \\ I Intellectual Disability Medicine, Department of General Practice, Erasmus Medical Centre, Rotterdam, The Netherlands \\ 2 Centre of Expertise in Intellectual Disabilities, Department of Allied Health, Ipse de Bruggen, Zoetermeer, The Netherlands \\ 3 Pediatric Physiotherapy and Rehabilitation, Biomed, University of Hasselt, Hasselt, Belgium \\ 4 Avans University of Applied Sciences, Department of Health Care, Breda, The Netherlands \\ 5 Prisma Foundation, Department of Health Care and Applied Sciences, Waalwijk, The Netherlands \\ 6 Physiotherapy Achter De Blauwe Deur, Department of Allied Health, Sint Michielsgestel, The Netherlands \\ 7 Department of Rehabilitation Medicine, School for Public Health and Primary care (CAPHRI), Maastricht University, Maastricht, \\ The Netherlands \\ 8 Adelante Center of Expertise in Rehabilitation and Audiology, Department of Allied Health, Valkenburg and Hoensbroek, The Netherlands
}

\begin{abstract}
Background This study aimed to determine the relationship between motor abilities and quality of life in children with severe multiple disabilities.

Methods In this cross-sectional study, motor abilities of 29 children (mean age 9.8 years; $45 \%$ girls) with severe multiple disabilities [IQ $<25$; Gross Motor Function Motor Classification System level V] were measured with the MOtor eVAluation in Kids with Intellectual and Complex disabilities (Movakic) questionnaire (completed by the child's physical therapist). Quality of life was measured with the Quality of Life-Profound Multiple Disabilities (QoL-PMD) questionnaire (completed by the child's parents).

Results A significantly moderate to high correlation was found between the total scores on the Movakic and the QoL-PMD ( $r=0.40, P=0.03)$, indicating that higher scores in motor abilities are associated
\end{abstract}

Correspondence: Dr. Sonja M. Mensch, Intellectual Disability Medicine, Department of General Practice, Erasmus Medical Centre, PO Box 2040, 3000 CA Rotterdam, The Netherlands (e-mail: sm.mensch@gmail.com). with a higher level of quality of life. Furthermore, significantly moderate to high correlations were found between the total score on the Movakic and the dimension Physical Well-Being, Development and Activities of the Qol-PMD. In multiple linear regression models, all significant bivariate relationships between the Movakic total scores and QoL-PMD dimensions remained significant after controlling for the Gross Motor Function Motor Classification System level. Conclusions In these children with severe multiple disabilities, motor abilities (as measured by Movakic) are moderately related to quality of life (as measured by the QoL-PMD).

Keywords severe multiple disabilities or profound intellectual and multiple disability, motor abilities, quality of life, cerebral palsy GMFCS IV-V, Movakic

\section{Background}

Motor abilities generally play an important role in independent functioning (Janssen et al. 2010). Adequate motor function in persons with motor 
S. M. Mensch et al. - Motor abilities and quality of life in children with SMD

disabilities contributes to a sense of independence and autonomy and improves the level of participation in daily life (Raz-Silberger et al. 20I5; Badia et al. 20I4; Schoenmakers et al. 2005). In children with severe multiple disabilities (SMD), motor abilities are severely compromised meaning these children are often unable to change body position, to take up and maintain an upright body position and moving around such as turning around, rolling and crawling. Motor abilities are comparable with the Gross Motor Function Motor Classification System (GMFCS) level IV/V (Palisano et al. 1997). These children are often wheelchair-bound and dependent on their social, instrumental and material environment for all activities of daily life. In addition, children with SMD have a profound or unspecified intellectual disability (IQ < 25) (American Psychiatric Association. 2013). Communicative functions are severely limited; children with SMD only communicate non-verbally or through body language. Furthermore, we earlier reported that these children have sensory disorders (such as visual impairment) and other co-morbidity such as feeding and respiratory problems, epilepsy and contractures (Mensch, Rameckers, Echteld, Penning, and Evenhuis, 2015). Despite the lack of internal motivation or initiation of children with SMD (Munde \& Vlaskamp., 20I5), stimulation of motor abilities will help them (to a certain extent) to influence their surroundings such as care-givers or parents, change their position, reach or shift towards a toy, actively participate in eating and other activities and ease personal hygienic care for their parents or other caregivers. So, motor abilities provide children with SMD with a degree of control over their own life and as such may positively influence their quality of life (QoL).

Quality of life can be defined as objective and subjective well-being of individuals within different domains, such as the physical, psychological, social, emotional, communicative and material domains (Felce \& Perry., I995; Felce. 1997). Several studies found a relationship between motor functioning and QoL. For example, Dickinson et al., who examined self-reported QoL of 8- to I2-year-old children with cerebral palsy $(n=500$, GMFCS IV-V I $4 \%$, IQ $<70$ $27 \%$ ) found that severely limited self-mobility was significantly associated with a reduced mean score for physical well-being (Dickinson et al. 2007). In a systematic review, Tsoi et al. found some positive effect of certain medicinal and motor control interventions on QoL in children with cerebral palsy ( $n=347$, average age 9.I years) (Tsoi et al. 20I2). In their study on pain, motor function and health-related QoL in children $(n=9 \mathrm{I}$, age $8-\mathrm{I} 9$ years, GMFCS level IV-V 51.6\%, severe cognitive impairment $30.8 \%$ ), Badia et al. found that motor impairment scores were significantly positively associated with physical and autonomy domains of QoL (Badia et al. 20I4). Maher et al. found a positive association between physical activity, social and physical QoL and happiness in young people with cerebral palsy ( $n=70$, mean age I3 years, GMFCS level IV-V I6\%) (Maher et al. 20I6). In another study on persons with SMD [ $n=49$, average age 23.7 (SD) I2.2 years], Petry et al. (2009a) examined the association between QoL, motor function, personal characteristics and characteristics of care settings. The authors found that characteristics of the medical conditions of the children were most strongly associated with the QOL-PMD scores, whereas other personal characteristics (e.g. age, gender, motor limitations and sensory limitations) were not.

In addition, some evidence that impaired motor abilities affect QoL was shown in children with cerebral palsy; in children with SMD, limited evidence has been provided. However, we hypothesise that this relationship might also be true in children with SMD, whose motor abilities are severely limited. By improving their motor abilities, these children might feel that they have more control over their environment, which might, in turn, have a beneficial effect on their QoL. However, data on relationships between motor function and QoL in these children are largely lacking.

Therefore, this study explores our hypothesis that in children with SMD, a higher level of motor ability will be related to a higher level of QoL. Specifically, associations were examined between different QoL dimensions and motor abilities in different bodily positions. In addition, independent associations were examined after controlling for possible confounders such as age, gender and GMFCS level.

\section{Methods}

\section{Study design and study population}

In this cross-sectional study, children aged $\leq_{\text {I } 8}$ years with SMD receiving care in specialised day-care 
S. M. Mensch et al. • Motor abilities and quality of life in children with SMD

centres were recruited from nine different care organisations for individuals with intellectual disabilities. Eligible for this study were children with SMD who had a profound intellectual disability (IQ < 25), motor abilities comparable with GMFCS levels IV or V (Palisano et al. I997) and sensory or other comorbid disorders.

A total of 34 physical therapists working in day-care centres were asked to select one or two of their clients with SMD; of these, 27 agreed to participate. All participating physical therapists had $\geq_{\text {IO-year }}$ experience working with children with SMD and had to be the therapist of the selected child with SMD for at least 3 months. Together, they selected 56 children who fulfilled the inclusion criteria. Of these, the parents or legal representatives of 29 children provided informed consent for participation. Table I shows the characteristics of the study sample; mean age was 9.8 (range $2-18$ ) years, and $45 \%$ was classified as GMFCS level V.

\section{Instruments}

\section{Motor abilities}

Motor abilities were measured with the MOtor eVAluation in Kids with Intellectual and Complex disabilities (Movakic) instrument; this is a digital questionnaire specifically developed for the evaluation of motor abilities in children with SMD (Mensch, Rameckers, Echteld, Penning, and Evenhuis, 2015). This instrument was developed because instruments applicable to children with severe disabilities were largely lacking (Mensch et al. 2015b) and the existing tests were inadequate (Mensch, Rameckers, Echteld, Penning, and Evenhuis, 2015).

Details on the structure of Movakic are presented in Table A.I. Motor abilities are distributed over I2 situations, each representing a client's body position: lying, sitting and standing, with or without the use of a device. Each situation consists of a cluster of items addressing four groups of motor abilities: maintaining position, activities, changing body position and moving around. Questions were asked about the extent to which manual support or support from a device is needed, the child's own activity and the extent of stimulating the child manually, that is 'facilitation' by enabling a child to actively participate in a certain motor ability.
Table I Demographic and diagnostic data of the study population

\begin{tabular}{|c|c|c|c|}
\hline & & $n=29$ & $\%$ \\
\hline \multirow[t]{2}{*}{ Gender } & Male & 13 & 45 \\
\hline & Female & 16 & 55 \\
\hline \multirow[t]{3}{*}{ Age in years } & $1-6$ & 3 & 10 \\
\hline & $6-12$ & 10 & 35 \\
\hline & $12-18$ & 16 & 55 \\
\hline \multirow[t]{3}{*}{ GMFCS $^{\dagger}$ level } & IV & 12 & 41 \\
\hline & $\mathrm{V}$ & 13 & 45 \\
\hline & Not scored & 4 & 14 \\
\hline \multirow[t]{5}{*}{ Diagnosis } & Cerebral palsy & 8 & 28 \\
\hline & Syndromes/gene mutations & 12 & 42 \\
\hline & Meningitis & I & 3 \\
\hline & Metabolic disease & I & 3 \\
\hline & Unknown & 7 & 24 \\
\hline Cognitive developmental & $0-6$ & 6 & 21 \\
\hline \multirow[t]{4}{*}{ level in months } & $6-12$ & 4 & 14 \\
\hline & $12-18$ & 2 & 7 \\
\hline & Unknown & 6 & 21 \\
\hline & Not scored & II & 38 \\
\hline \multirow[t]{8}{*}{ Comorbidity } & Epilepsy & 12 & 41 \\
\hline & $\mathrm{PEG}^{\ddagger}$ tube & 7 & 24 \\
\hline & Scoliosis & 7 & 24 \\
\hline & Visual impairment & 14 & 48 \\
\hline & Respiratory problem & 4 & 13 \\
\hline & $\begin{array}{l}\text { Secondary problem } \\
\text { (contractures) }\end{array}$ & 8 & 27 \\
\hline & Other ${ }^{\S}$ & 7 & 24 \\
\hline & Not scored & 11 & 37 \\
\hline \multirow[t]{8}{*}{ Assistive devices ${ }^{\pi}$} & Wheelchair & 16 & 55 \\
\hline & Standing device & 11 & 38 \\
\hline & Walking aid & 7 & 24 \\
\hline & (Semi) Orthopaedic & 9 & 31 \\
\hline & shoes & & \\
\hline & Orthotics & 10 & 35 \\
\hline & Lying device & 3 & 10 \\
\hline & Not scored & 11 & 38 \\
\hline
\end{tabular}

${ }^{\dagger}$ GMFCS, Gross Motor Function Classification System (Palisano et al. 1997). To indicate the level of motor abilities for the total group of children with SMD, the GMFCS was used.

†PEG tube: percutaneous endoscopic gastrostomy tube.

\$Other: additional comorbid conditions, e.g. heart disease, hearing disorders, diabetes mellitus and gastro-oesophageal reflux disease. "Assistive devices and aids for personal mobility (World Health Organisation, 2008)

Because all children have different abilities/disabilities and different therapeutic goals, only situations that are relevant to the child need to be scored, based on the therapist's experience of the child's motor abilities. All items were scored on a 5-point Likert scale. The maximum total scores of the I2 situations differ because of the variable number of

(C) 2018 MENCAP and International Association of the Scientific Study of Intellectual and Developmental Disabilities and John Wiley \& Sons Ltd 
S. M. Mensch et al. - Motor abilities and quality of life in children with SMD

the items. Therefore, situation scores and total Movakic scores are converted into percentage scores (range O-IOO). Within each chosen situation, a higher score is associated with better motor ability.

Additional information on the items/sub-questions of Movakic is presented in Appendix A.

Movakic has been judged clinically relevant and suitable for the target population and has adequate content validity (Mensch, Rameckers, Echteld, Penning, and Evenhuis, 20I5). Its test-retest and inter-rater reliability are excellent or good (ICC 0.720.98) (Mensch et al. 2015a), its construct validity is $\operatorname{good}(r=0.50-0.7 \mathrm{I})$, and Movakic is responsive to change resulting from events that might impact motor ability (Mensch et al. 2016).

\section{Quality of life}

In these children with SMD, QoL was measured with the Quality of Life-Profound Multiple Disabilities (QoL-PMD) questionnaire (Petry et al. 2008, Petry et al. 2009a; Petry et al. 2009b). Because of the communication difficulties of children with SMD, proxy measures of QoL in multiple dimensions were assessed. The QoL-PMD is a multidimensional questionnaire consisting of 55 items/statements related to the life of the child with SMD and divided into six sub-scales: Physical well-being, Material wellbeing, Communication and influence, Socioemotional well-being, Development and Activities. The items are scored on a 4-point scale (agree, partly agree, disagree and undecided). A score of 0-100\% can be obtained, both on the total score and on the sub-scale score. A higher score indicates a better QoL. Psychometric examination of the QoL-PMD (Petry et al. 2008, Petry et al. 2009b) has shown good internal consistency for the total questionnaire ( $\alpha=0.90-0.92)$ and for the sub-scales $(\alpha=0.63-0.88)$. In addition, correlations between the QoL-PMD and the Mood Interest and Pleasure Questionnaire (MIPQ) ( $r=0.3 \mathrm{I}, P<0.00 \mathrm{I}$ ), and between the QoL-PMD and a general measure of the QoL (using a Io-point scale) ( $r=0.44, P<0.00 \mathrm{I}$ ), have shown moderate construct validity of the QoL-PMD in children with SMD.

\section{Procedure}

For all participants, informed consent was obtained from their parents or legal representatives.
Physiotherapists underwent training in the proper use of the Movakic instrument and the study procedure; this was provided by the researcher (S.M.) and an expert group who developed the instrument. At baseline, therapists provided information on the child's gender, age, cognitive developmental age, GMFCS level, diagnosis, comorbid conditions and assistive devices used. Motor abilities were measured with Movakic as completed by the child's physiotherapist; QoL was measured with the QoLPMD as completed by the child's parents. Both measures had to be completed within a maximum of 3 months because, during this period, no changes were expected. To control for possible changes, all physiotherapists were asked to report on any factors (e.g. medication change, surgery, pain or increase of contractures) that might influence motor abilities during the 3-month period. In the case that a relevant event had occurred, that child was excluded from further analysis.

\section{Analyses}

Characteristics of the study sample were examined. Movakic scores were obtained in two ways: (I) for each child, the average of all completed situations of Movakic was calculated in a total Movakic score and (2) scores of the chosen situations of Movakic were averaged for the three body positions 'lying' (situation I-6), 'sitting' (situation 7-10) and 'standing' (situation II-I2), and for each child, the average score per body position was calculated.

Normality of the Movakic and QoL-PMD data was checked by using the Kolmogorov-Smirnov and was found sufficient. Using Pearson's correlation coefficient ( $r$ ), Movakic sub-scores in the different body positions (lying, sitting and standing) were correlated with both QoL sub-scores on dimensions and total QoL score. The same analysis was used to correlate the Movakic total score with both the QoL sub-scores and total QoL score. The magnitude of correlation coefficients was interpreted by using the guidelines of Cohen (Cohen. I992), that is 0.10-0.29 = small, $0.30-0.49=$ medium and $>0.50=$ large. A positive correlation means that high scores on motor abilities often co-occur with high scores on QoL; this is also the case for low scores. Independent relationships between motor abilities and QoL were tested by using multiple

(C) 2018 MENCAP and International Association of the Scientific Study of Intellectual and Developmental Disabilities and John Wiley \& Sons Ltd 
S. M. Mensch et al. - Motor abilities and quality of life in children with SMD

linear regression analysis models with the QoL dimensions (dependent variables) that showed a significant correlation with Movakic sub-scores on body positions (independent variables). In model I, gender, age and GMFCS scores were entered into the equation after which, in model 2, the Movakic motor ability total or sub-scale scores were entered into the equation. For each of these Movakic scores, separate regression equations were tested. In order to control for the covariates gender, age and GMFCS score, the explained variance $\left(R^{2}\right)$ was calculated for both models. The difference between the $R^{2}$ values of models I and 2 was interpreted as the uniquely explained variance in QoL scores using only the Movakic scores. In order to check for the assumptions of the multiple linear regression analyses, we inspected histograms of the dependent and independent variables and performed Kolmogorov-Smirnov tests in order to detect deviations from the normal distribution. Scatterplots between the dependent and independent variables were used to indicate deviations from the assumption of a linear relationship.

Homoscedasticity was checked with scatterplots of residuals and predicted values. Lastly, multicollinearity was tested by using the variance inflation factor. Multicollinearity was considered absent if variance inflation factor $<$ IO.

All analyses were done by using SPSS/PASW STATISTICS version 2 I (SPSS Inc., Chicago, IL, USA). A $P$-value $\leq 0.05$ was considered statistically significant.

\section{Results}

In all children, both Movakic and the QoL-PMD were measured within a period of 2-I2 (mean 7.2) weeks; no meaningful events were observed in any child during this period.

Bivariate correlations between Movakic and the QoL sub-scales and total scores are presented in Table 2. A significant and moderately high correlation ( $r=0.40, P=0.03$ ) was found between the total Movakic score and the total QoL-PMD score. Significant bivariate moderate correlations were also found between the total Movakic score and the QoLPMD dimensions Physical well-being, Development and Activities. Motor ability in the lying and sitting body position were significantly positively correlated with the QoL-PMD dimension Development (moderately to substantially). Motor ability in the sitting body position was also significantly positively correlated (moderately) with the dimension Physical well-being and the total QoL-PMD score. Motor ability in the standing body position had a strong significant positive correlation with the dimension Activities and the total QoL-PMD score.

The assumption tests for multiple linear regression did not indicate deviations from the assumptions for multiple linear regression analysis. Mean QoL-PMD and Movakic scores and the results of the multiple regression analysis are reported in Table 3. As significant bivariate correlations were found between the total Movakic score and the QoL-PMD dimensions Physical well-being, Development and

Table 2 Bivariate correlations between Movakic and the quality of life scores

Quality of life dimensions

\begin{tabular}{|c|c|c|c|c|c|c|c|}
\hline $\begin{array}{l}\text { Movakic } \\
\text { Body positions }\end{array}$ & $\begin{array}{c}\text { Physical } \\
\text { well-being } \\
r^{\dagger}(P)\end{array}$ & $\begin{array}{c}\text { Material } \\
\text { well-being } \\
r^{\dagger}(P)\end{array}$ & $\begin{array}{c}\text { Communication } \\
\text { and Influence } \\
r^{\dagger}(P)\end{array}$ & $\begin{array}{c}\text { Socio-emotional } \\
\text { well-being } \\
r^{\dagger}(P)\end{array}$ & $\begin{array}{l}\text { Development } \\
r^{\dagger}(P)\end{array}$ & $\begin{array}{c}\text { Activities } \\
r^{\dagger}(P)\end{array}$ & $\begin{array}{c}\text { Total } \\
\text { QoL-PMD } \\
r^{\dagger}(P)\end{array}$ \\
\hline Lying $(n=20)$ & $0.43(0.06)$ & $0.18(0.46)$ & $-0.17(0.49)$ & $0.30(0.20)$ & $0.5 I *(0.02)$ & $0.34(0.15)$ & $0.38(0.10)$ \\
\hline Sitting $(n=25)$ & $0.49 *(0.01)$ & $0.016(0.46)$ & $0.06(0.78)$ & $0.29(0.16)$ & $0.45 *(0.03)$ & $0.36(0.08)$ & $0.4 I^{*}(0.04)$ \\
\hline Standing $(n=17)$ & $0.30(0.25)$ & $-0.05(0.85)$ & $0.46(0.06)$ & $0.43(0.09)$ & $0.23(0.40)$ & $0.61^{* * *}(0.01)$ & $0.53^{*}(0.03)$ \\
\hline Total Movakic $(n=29)$ & $0.43 *(0.02)$ & $0.09(0.65)$ & $0.08(0.67)$ & $0.32(0.09)$ & $0.46 *(0.01)$ & $0.38^{*}(0.05)$ & $0.40 *(0.03)$ \\
\hline
\end{tabular}

${ }^{\dagger}$ Pearson (bivariate) correlation coefficient.

$* P \leq 0.05$.

*** $P \leq 0.01$.

(C) 2018 MENCAP and International Association of the Scientific Study of Intellectual and Developmental Disabilities and John Wiley \& Sons Ltd 
S. M. Mensch et al. • Motor abilities and quality of life in children with SMD

Table 3 Mean Movakic scores and independent relationships (standardised regression coefficients) between Movakic and quality of life scores.

\begin{tabular}{|c|c|c|c|c|c|c|c|c|c|}
\hline \multirow{4}{*}{$\begin{array}{l}\text { Movakic } \\
\text { Body positions }\end{array}$} & \multirow[b]{4}{*}{ Mean (SD) } & \multicolumn{8}{|c|}{ Quality of life dimensions } \\
\hline & & \multirow{2}{*}{\multicolumn{2}{|c|}{$\begin{array}{l}\text { Physical well-being } \\
\text { (Mean = 55.3; } \\
\text { SD = 20.5) }\end{array}$}} & \multirow{2}{*}{\multicolumn{2}{|c|}{$\begin{array}{l}\text { Development } \\
\begin{array}{c}\text { Mean = 64.8; } \\
\text { SD = 21.2) }\end{array}\end{array}$}} & \multirow{2}{*}{\multicolumn{2}{|c|}{$\begin{array}{c}\text { Activities } \\
\begin{array}{c}\text { Mean = 70.4; } \\
\text { SD = I7.0) }\end{array}\end{array}$}} & \multirow{2}{*}{\multicolumn{2}{|c|}{$\begin{array}{l}\text { QoL total } \\
\text { (Mean = 65.3; } \\
\text { SD = 14.7) }\end{array}$}} \\
\hline & & & & & & & & & \\
\hline & & $\boldsymbol{\beta}^{\dagger}$ & $R^{2 \ddagger}$ & $\beta^{\dagger}$ & $R^{2 \ddagger}$ & $\boldsymbol{\beta}^{\dagger}$ & $R^{2 \ddagger}$ & $\beta^{\dagger}$ & $R^{2 \ddagger}$ \\
\hline Lying & $0.60(0.22)$ & $0.66^{*}$ & $0.34^{*}$ & $0.60 *$ & $0.29 *$ & 0.44 & 0.15 & $0.55 *$ & $0.24 *$ \\
\hline Sitting & $0.56(0.22)$ & $0.75^{*} * k$ & $0.38^{*}$ & $0.57^{*}$ & $0.22 *$ & 0.48 & 0.15 & 0.49 & 0.16 \\
\hline Standing & $0.60(0.19)$ & 0.19 & 0.03 & 0.01 & 0.00 & 0.46 & 0.16 & 0.34 & 0.09 \\
\hline Movakic total & $0.58(0.20)$ & $0.64^{* \cdots * k}$ & $0.30 * * *$ & $0.52^{*}$ & $0.20 *$ & $0.5 I^{*}$ & $0.19 *$ & $0.48 *$ & $0.17^{*}$ \\
\hline
\end{tabular}

†Standardised regression coefficient controlling for gender, age and GMFCS levels.

‡Proportion explained variance of the regression model $\left(R^{2}\right)$; significance level indicates a significant change in the $F$ statistic after entering the Movakic dimension.

$* P \leq 0.05$.

*** $P \leq 0.01$.

Activities, and between Movakic body position scores and these same QoL-PMD dimensions, these QoL dimensions were used for the multiple regression analyses. The scores on the Physical well-being, Development and Activities dimensions were relatively high, with a mean total score of 65.3 (SD I4.7)\%. After controlling for gender, age and GMFCS levels in the multiple linear regression models, all significant bivariate relationships between the Movakic total scores and the QoL-PMD dimensions and the QoL-PMD total score remained significant. In this latter analysis, the relationship between the dimension Activities and the body position standing, and between the total QoL-PMD and the body positions sitting and standing, lost their significant correlation. The addition of the Movakic variables on body positions into the regression models resulted in significant additions to the proportion of explained variance. Most models explained a fair amount of variance. The relationships between gender, age, GMFCS levels and the QoL-PMD variables were not significant in any of the regression models, except for the GMFCS in the regression model with the body position lying and the QoL dimension Physical well-being $\left(\beta=0.66 ; R^{2}=0.23\right.$; $P<0.05)$.

Table 4 shows the results of the last step of the multiple regression analysis, that is independent relationships between total Movakic and the different domains of the QoL scores (total, Physical well-being, Development and Activities). After controlling for the covariates, the Movakic total score explained a significant $17 \%$ more of the variance in the total QoL score $(B=0.48 ; P=0.05)$ than the model using only the covariates. In addition, the model accounted for $30 \%$ more of the variance in the QoL domain Physical well-being ( $\beta=0.64 ; P=0.0 \mathrm{I}$ ), $20 \%$ in the $\mathrm{QoL}$ domain Development $(B=0.52 ; P=0.03)$ and $19 \%$ in the QoL domain Activity ( $B=0.5 \mathrm{I} ; P=0.03$ ). The total model accounted for $25 \%$ of the variance.

\section{Discussion}

This first study focusing on the relation of motor abilities and QoL of children with SMD shows that a relatively higher level of motor abilities is significantly related to higher QoL. Motor ability is most strongly correlated with the QoL dimension Physical wellbeing and, to a lesser extent, to the dimensions Development and Activities. Multiple regression analyses showed significant independent relationships between motor abilities and QoL for almost all domains of motor abilities.

Quality of life is an important aim of treatment for children with SMD. The results of this study show that different motor abilities show a relationship with 
S. M. Mensch et al. • Motor abilities and quality of life in children with SMD

Table 4 Regression analyses showing independent relationships between Movakic and quality of life (total and relevant domain scores).

\begin{tabular}{|c|c|c|c|c|c|c|c|c|c|c|}
\hline & $R^{2}$ & $\Delta R^{2}$ & $\Delta \mathbf{F}$ & $P \Delta F$ & Independent variable & B & SE & $\beta$ & $t$ & $P$ \\
\hline \multicolumn{11}{|l|}{ QoL-PMD total } \\
\hline \multirow[t]{5}{*}{ Movakic total } & 0.25 & 0.17 & 4.56 & 0.05 & & & & & & \\
\hline & & & & & Gender & -3.32 & 5.44 & -0.12 & -0.61 & 0.55 \\
\hline & & & & & Age & 0.47 & 0.59 & 0.16 & 0.79 & 0.44 \\
\hline & & & & & GMFCS & 2.34 & 6.34 & 0.08 & 0.37 & 0.72 \\
\hline & & & & & Movakic total & 31.83 & 14.9 & 0.48 & 2.14 & 0.05 \\
\hline \multirow[t]{5}{*}{ Movakic lying } & 0.27 & 0.24 & 4.85 & 0.04 & & & & & & \\
\hline & & & & & Gender & 0.88 & 5.61 & 0.04 & 0.16 & 0.88 \\
\hline & & & & & Age & -0.01 & 0.55 & -0.01 & -0.03 & 0.98 \\
\hline & & & & & GMFCS & 9.60 & 6.13 & 0.40 & 1.57 & 0.14 \\
\hline & & & & & Movakic lying & 30.30 & 13.76 & 0.55 & 2.20 & 0.04 \\
\hline \multirow[t]{5}{*}{ Movakic sitting } & 0.28 & 0.16 & 3.61 & 0.08 & & & & & & \\
\hline & & & & & Gender & -4.62 & 6.42 & -0.16 & -0.72 & 0.48 \\
\hline & & & & & Age & 0.44 & 0.76 & 0.13 & 0.58 & 0.57 \\
\hline & & & & & GMFCS & 2.38 & 7.58 & 0.08 & 0.31 & 0.76 \\
\hline & & & & & Movakic sitting & 31.18 & 16.38 & 0.50 & 1.90 & 0.08 \\
\hline \multirow[t]{5}{*}{ Movakic standing } & 0.43 & 0.09 & 1.67 & 0.22 & & & & & & \\
\hline & & & & & Gender & -4.8 & 7.62 & -0.23 & -0.63 & 0.54 \\
\hline & & & & & Age & 1.23 & 0.91 & 0.48 & 1.35 & 0.20 \\
\hline & & & & & GMFCS & -6.52 & 5.74 & -0.31 & -1.14 & 0.28 \\
\hline & & & & & Movakic standing & 19.25 & 14.92 & 0.34 & 1.29 & 0.22 \\
\hline \multicolumn{11}{|c|}{ QoL-PMD Physical well-being } \\
\hline \multirow[t]{5}{*}{ Movakic total } & 0.34 & 0.30 & 9.16 & 0.01 & & & & & & \\
\hline & & & & & Gender & -3.53 & 7.38 & -0.09 & -0.48 & 0.64 \\
\hline & & & & & Age & 0.32 & 0.81 & 0.08 & 0.40 & 0.69 \\
\hline & & & & & GMFCS & 10.95 & 8.60 & 0.27 & 1.27 & 0.22 \\
\hline & & & & & Movakic total & 61.15 & 20.21 & 0.64 & 3.03 & 0.01 \\
\hline \multirow[t]{5}{*}{ Movakic lying } & 0.39 & 0.34 & 8.36 & 0.01 & & & & & & \\
\hline & & & & & Gender & 2.25 & 7.93 & 0.06 & 0.28 & 0.78 \\
\hline & & & & & Age & -0.31 & 0.78 & -0.09 & -0.40 & 0.69 \\
\hline & & & & & GMFCS & 19.32 & 8.66 & 0.52 & 2.23 & 0.04 \\
\hline & & & & & Movakic lying & 56.16 & 19.43 & 0.66 & 2.89 & 0.01 \\
\hline \multirow[t]{5}{*}{ Movakic sitting } & 0.45 & 0.38 & 10.88 & 0.01 & & & & & & \\
\hline & & & & & Gender & -3.90 & 8.12 & -0.09 & -0.48 & 0.64 \\
\hline & & & & & Age & 0.40 & 0.96 & 0.08 & 0.42 & 0.68 \\
\hline & & & & & GMFCS & 14.26 & 9.58 & 0.34 & 1.49 & 0.16 \\
\hline & & & & & Movakic sitting & 68.34 & 20.72 & 0.75 & 3.30 & 0.01 \\
\hline \multirow[t]{5}{*}{ Movakic standing } & 0.17 & 0.03 & 0.35 & 0.57 & & & & & & \\
\hline & & & & & Gender & -12.01 & 16.94 & -0.31 & -0.71 & 0.49 \\
\hline & & & & & Age & 2.03 & 2.02 & 0.44 & 1.01 & 0.34 \\
\hline & & & & & GMFCS & -4.79 & 12.75 & -0.12 & -0.38 & 0.71 \\
\hline & & & & & Movakic standing & 19.65 & 33.15 & 0.19 & 0.59 & 0.57 \\
\hline \multicolumn{11}{|c|}{ QoL-PMD Development } \\
\hline \multirow[t]{5}{*}{ Movakic total } & 0.31 & 0.20 & 5.81 & 0.03 & & & & & & \\
\hline & & & & & Gender & 10.43 & 8.07 & 0.24 & 1.30 & 0.21 \\
\hline & & & & & Age & 0.37 & 0.88 & 0.08 & 0.42 & 0.68 \\
\hline & & & & & GMFCS & 2.42 & 9.41 & 0.06 & 0.26 & 0.80 \\
\hline & & & & & Movakic total & 53.26 & 22.10 & 0.52 & 2.41 & 0.03 \\
\hline \multirow[t]{4}{*}{ Movakic lying } & 0.40 & 0.29 & 7.10 & 0.02 & & & & & & \\
\hline & & & & & Gender & $|4.0|$ & 9.44 & 0.30 & 1.48 & 0.16 \\
\hline & & & & & Age & -0.09 & 0.93 & -0.02 & -0.10 & 0.92 \\
\hline & & & & & GMFCS & 11.57 & 10.31 & 0.26 & 1.12 & 0.28 \\
\hline
\end{tabular}

(C) 2018 MENCAP and International Association of the Scientific Study of Intellectual and Developmental Disabilities and John Wiley \& Sons Ltd 
S. M. Mensch et al. • Motor abilities and quality of life in children with SMD

Table 4. (Continued)

\begin{tabular}{|c|c|c|c|c|c|c|c|c|c|c|}
\hline & $R^{2}$ & $\Delta R^{2}$ & $\Delta \mathbf{F}$ & $P \Delta F$ & Independent variable & B & SE & $\beta$ & $t$ & $P$ \\
\hline & & & & & Movakic lying & 61.63 & 23.13 & 0.60 & 2.67 & 0.02 \\
\hline \multirow[t]{5}{*}{ Movakic sitting } & 0.32 & 0.22 & 5.10 & 0.04 & & & & & & \\
\hline & & & & & Gender & 13.03 & 9.80 & 0.28 & 1.33 & 0.20 \\
\hline & & & & & Age & 0.26 & 1.15 & 0.05 & 0.22 & 0.83 \\
\hline & & & & & GMFCS & 5.02 & 11.56 & 0.11 & 0.43 & 0.67 \\
\hline & & & & & Movakic sitting & 56.44 & 25.00 & 0.57 & 2.26 & 0.04 \\
\hline \multirow[t]{5}{*}{ Movakic standing } & 0.36 & 0.00 & 0.00 & 0.97 & & & & & & \\
\hline & & & & & Gender & 14.49 & 12.72 & 0.43 & 1.14 & 0.28 \\
\hline & & & & & Age & 0.50 & 1.52 & 0.13 & 0.33 & 0.75 \\
\hline & & & & & GMFCS & -14.11 & 9.57 & -0.42 & -1.47 & 0.17 \\
\hline & & & & & Movakic standing & 0.99 & 24.89 & 0.01 & 0.04 & 0.97 \\
\hline \multicolumn{11}{|l|}{ QoL-PMD Activity } \\
\hline \multirow[t]{5}{*}{ Movakic total } & 0.26 & 0.19 & 5.25 & 0.03 & & & & & & \\
\hline & & & & & Gender & 1.34 & 5.88 & 0.04 & 0.23 & 0.82 \\
\hline & & & & & Age & 0.50 & 0.64 & 0.16 & 0.78 & 0.45 \\
\hline & & & & & GMFCS & 3.71 & 6.85 & 0.12 & 0.54 & 0.59 \\
\hline & & & & & Movakic total & 36.86 & 16.10 & 0.51 & 2.29 & 0.03 \\
\hline \multirow[t]{5}{*}{ Movakic lying } & 0.18 & 0.15 & 2.74 & 0.12 & & & & & & \\
\hline & & & & & Gender & 2.17 & 7.39 & 0.07 & 0.29 & 0.77 \\
\hline & & & & & Age & 0.21 & 0.72 & 0.07 & 0.29 & 0.77 \\
\hline & & & & & GMFCS & 7.53 & 8.07 & 0.25 & 0.93 & 0.37 \\
\hline & & & & & Movakic lying & 29.97 & 18.10 & 0.44 & 1.66 & 0.12 \\
\hline \multirow[t]{5}{*}{ Movakic sitting } & 0.24 & 0.15 & 3.20 & 0.09 & & & & & & \\
\hline & & & & & Gender & -0.15 & 6.80 & -0.01 & -0.02 & 0.98 \\
\hline & & & & & Age & 0.34 & 0.80 & 0.09 & 0.43 & 0.68 \\
\hline & & & & & GMFCS & 0.92 & 8.02 & 0.03 & 0.11 & 0.91 \\
\hline & & & & & Movakic sitting & 31.03 & 17.35 & 0.48 & 1.79 & 0.09 \\
\hline \multirow[t]{5}{*}{ Movakic standing } & 0.50 & 0.16 & 3.48 & 0.09 & & & & & & \\
\hline & & & & & Gender & 7.45 & 9.60 & 0.26 & 0.78 & 0.46 \\
\hline & & & & & Age & 0.36 & 1.14 & 0.11 & 0.31 & 0.76 \\
\hline & & & & & GMFCS & -8.20 & 7.23 & -0.29 & -1.13 & 0.28 \\
\hline & & & & & Movakic standing & 35.04 & 18.79 & 0.46 & 1.87 & 0.09 \\
\hline
\end{tabular}

$R^{2}, R$ square; $\Delta R^{2}, R$ square change; $\Delta F, F$ change; $P \Delta F$, significant change in $F ; B$, unstandardised coefficient values; SE, standard error; $\beta$, beta; $t, t$ test; $P$, level of significance.

QoL that is not explained by the GMFCS level. Thus, supporting children in improving their motor abilities, which enables them to have more sense of control over their environment, may contribute to their QoL. This study provides justification for the assumption that stimulation of motor abilities, even for those children with a very low level, will most likely promote their sense of well-being. Although QoL is considered to be a multidimensional construct, there is no consensus regarding the relevant domains or the content of the QoL domains (Tsoi et al. 20I2). In their review, Albers et al. found 29 questionnaires on QoL in which various domains (e.g. physical, psychological, social, spiritual, emotional, communicative and material aspects) were identified as being important for a person's total well-being (Albers et al. 2010). In the present study, positive relationships were found between the QoL domains Physical well-being, Development and Activities and motor abilities. In contrast, no significant relationship was found between motor abilities and the QoL domains Material well-being, Communication and influence and Socio-emotional well-being. In the present study, the QoL domains found to be positively correlated with the level of motor ability seem relevant for the study population. Although QoL is a broad concept with many possible domains, it is important to predetermine the rationale for 
S. M. Mensch et al. - Motor abilities and quality of life in children with SMD

measuring QoL in any specific population. In the present study population, the three QoL domains Physical well-being, Development and Activities correlate positively with motor abilities; however, this may not necessarily apply to another population.

Our findings are consistent with earlier studies, in which motor abilities were associated with QoL in groups of children with other disabilities. For example, Dickinson et al. found that children with cerebral palsy with poorer walking ability had poorer physical well-being scores (Dickinson et al. 2007), and Shelly et al. concluded that physical well-being domains (i.e. ability in participation and using arms and legs) of QoL are more strongly associated with functioning in general than psychosocial well-being domains (Shelly et al. 2008). In children with spina bifida, Schoenmakers et al. showed that being able to move independently was much more important for daily life function and QoL than other medical indicators of the disorder (Schoenmakers et al. 2005). Raz-Silbiger et al. concluded that gross motor skills of children with developmental coordination disorders are somewhat related to the physical and school dimensions of their QoL (Raz-Silbiger et al. 2015). Finally, in a study by Petry et al. (2009b) that examined the association between QoL, motor function, personal characteristics and characteristics of care settings in people with SMD, the authors, surprisingly, found no significant relation between motor limitation and QoL scores. However, in that study, the absence of such a relationship was insufficiently discussed because motor limitations were operationalised by the number of physical limitations in body parts, muscle tone and deformities, and not by measuring the level of motor abilities.

Adding to the available body of knowledge, the results of the present study underline the importance of stimulating motor abilities in this severely disabled group of children. Moreover, small changes in motor ability in this population are important, because a marked positive relationship was found between motor ability and the QoL domain of Physical well-being.

We expected Movakic to be related to all QoL components, but only the QoL sub-scales were related to physical aspects and/or physical functioning. This finding is congruent with the idea that stimulation of motor abilities will help the children to exert a certain degree of control over their lives. Improved motor abilities may aid the children in participating in and interacting with their surroundings and other people, for example by changing their position, reaching or shifting towards a toy and actively participating in eating and other activities. Apparently, these benefits do not extend to the sub-scales material, socio-emotional and communication/influence of QoL.

It should be noted that the motor ability of children with SMD is severely compromised and support is often needed for them to complete daily activities; this was an important fact in the development of Movakic. The expert group concluded that in this group of children, motor abilities are mostly based on support from other persons through facilitation of movement and support through assistive devices in combination with activity of the child (Mensch, Rameckers, Echteld, Penning, and Evenhuis, 2015). As was shown in this latter study, the tests available to evaluate motor abilities, applicable to children with motor disabilities, did not allow for manual support. Therefore, a change in motor abilities, as measured by Movakic, is to a great extent dependent on a change in the level of support or facilitation, as well as on a change in the level of activity of the children themselves. Again, this supports our statement that active participation of the child during all activities of daily life (i.e. by stimulating motor abilities) is a prerequisite to be more active in controlling part of the environment of these children, which influences their QoL.

A limitation of the present study was the small sample size, which may influence the correlation analyses. As a result, standard deviations for both scores seem large; this is probably because of the low numbers and the heterogeneous composition of the participants; this usually leads to a reduced possibility for a significant result. Thus, it is possible that, for example moderate relationships might have been significant had higher numbers been included and/or had the group been more homogeneous.

Despite the small size of the study population, children of nine different care organisations were included, making the results more representative for the Dutch population. Another issue is that motor abilities of these children were measured in a body position that is relevant to the individual child. For each child, the total score and the body position 
S. M. Mensch et al. - Motor abilities and quality of life in children with SMD

scores of Movakic are based on the scores of these relevant situations and, thus, can differ per child. Therefore, the scores of the motor abilities do not express the motor abilities in general. On the other hand, the theoretical framework of Movakic was based on the fact that instruments measuring general motor abilities are not relevant/applicable to children with SMD (Mensch, Rameckers, Echteld, Penning, and Evenhuis, 2015). Thus, there simply is no instrument that measures general motor abilities in this population and it is not feasible to create such an instrument because of the characteristics and heterogeneity of these children.

Furthermore, we did not perform a Bonferronicorrection for multiple tests of the same construct. Multiple testing within a cluster of variables may lead to an undesirable increase of Type I error. We did not perform the correction, because Bonferronicorrections are often criticised to be overly conservative. More importantly, focusing on Type I error neglects the equally important statistical power. Performing a Bonferroni-correction would lead to loss of statistical power, which is problematic given the small sample size.

Based on the knowledge that many variables can influence QoL (both positively and negatively), health professionals are urged to apply all available evidence to make the lives of these children more pleasant. More specifically, based on the results of this study, we recommend that physical therapists invest in interventions that focus on stimulating and activating children with SMD, with the aim of increasing their motor abilities. Parents and caregivers can play an important role in the success of this intervention. Therefore, after completing Movakic, we recommend involving parents and caregivers. Discussing the scores per item will help them to better understand the need to invest their time in stimulating motor abilities and achieving goals in the domain of motor abilities.

In this first study among children with SMD, only cross-sectional relationships were examined. A longitudinal study design is recommended to evaluate the influence of changes in motor abilities on QoL. A randomised controlled trial with a large study population and a longer period of intervention, aimed at improving motor abilities, is recommended. An earlier study on the responsiveness and validity of Movakic showed the importance and multitude of life events that children with SMD have to deal with (Mensch et al. 2016). Therefore, the relationship between carefully inventoried events (e.g. change in medication, disease, surgery and interventions) and their influence on QoL should be considered in future studies in this group of children.

\section{Conclusion}

This study shows that motor abilities in children with SMD are related to QoL. Better motor abilities were moderately associated with higher QoL levels, indicating the importance of improving motor abilities, even in this severely disabled group of children.

\section{Declaration of interests}

We certify that no party that contributed to the results of this research has or will benefit from its publication nor will any organisation with which we are associated. We agree this paper meets the standards of expected ethical behaviour. The Medical Ethical Committee of the Erasmus Medical Center approved this study (MEC 2010-236). If applicable, we certify that all financial and material support for this research and work are clearly identified in the title page of the manuscript. There are no conflicts to declare.

\section{Acknowledgments}

Ipse de Bruggen, care organisation for people with intellectual disabilities, and Nuts Ohra Fund (no. IIO2-045) financed this research. The authors are grateful to the participating therapists for their accurate and convincing collaboration. These participating therapists were from different care organisations all over the Netherlands; Kentalis, 's Heeren Loo, ASVZ, Zozijn, Stichting Tragel, Esdégé Reigersdaal, Kleur (Dichterbij), ZMLK school de Kom and Ipse de Bruggen. In addition, the authors pay tribute to Rob Rieken for his detailed editing.

\section{References}

Albers G., Echteld M. A., de Vet H. C., OnwuteakaPhilipsen B. D., van der Linden M. H. \& Deliens L. (2010) Evaluation of quality-of-life measures for use in

(C) 2018 MENCAP and International Association of the Scientific Study of Intellectual and Developmental Disabilities and John Wiley \& Sons Ltd 
S. M. Mensch et al. - Motor abilities and quality of life in children with SMD

palliative care: a systematic review. Palliative Medicine 24, I7-37.

American Psychiatric Association (APA) (2013) Diagnostic and Statistical Manual of Mental Disorders, 5th edn. American Psychiatric Association, Washington DC.

Badia M., Riquelme I., Orgaz B., Acevedo R., Longo E. \& Montoya P. (2014) Pain, motor function and healthrelated quality of life in children with cerebral palsy as reported by their physiotherapists. BMC Pediatrics $\mathbf{I 4}$, I92-7.

Cohen J. (1992) A power primer. Psychological Bulletin II2, I55-9.

Dickinson H. O., Parkinson K. N., Ravens-Sieberer U., Schirripa G., Thyen U., Arnaud C. et al. (2007) Selfreported quality of life of 8-I2-year-old children with cerebral palsy: a cross-sectional European study. Lancet 369, $217 \mathrm{I}-8$.

Felce D. \& Perry J. (1995) Quality of life: its definition and measurement. Research in Developmental Disabilities. I6, $5 \mathrm{I}-74$.

Felce D. (1997) Defining and applying the concept of quality of life. Fournal of Intellectual Disability Research 4I, I26-35.

Janssen C. G., Voorman J. M., Becher J. G., Dallmeijer A. J. \& Schuengel C. (2010) Course of health-related quality of life in 9-I6-year-old children with cerebral palsy: associations with gross motor abilities and mental health. Disability and Rehabilitation 32, 344-5I.

Maher C. A., Toohey M. \& Ferguson M. (2016) Physical activity predicts quality of life and happiness in children and adolescents with cerebral palsy. Disability and Rehabilitation 38, 865-9.

Mensch S. M., Echteld M. A., Evenhuis H. M. \& Rameckers E. A. A. (2016) Construct validity and responsiveness of Movakic; an instrument for the evaluation of motor abilities in children with severe multiple disabilities. Research in Developmental Disabilities 59, 194-201.

Mensch S. M., Rameckers E. A. A., Echteld M. A. \& Evenhuis H. M. (2015a) Reliability of Movakic; an instrument to evaluate motor abilities in children with severe multiple disabilities (Part-II). Physical Medicine and Rehabilitation - International 2, I-5.

Mensch S. M., Rameckers E. A. A., Echteld M. A. \& Evenhuis H. M. (2015b) Instruments for the evaluation of motor abilities for children with severe multiple disabilities: a systematic review of the literature. Research in Developmental Disabilities 47, I85-98.

Mensch S. M., Rameckers E. A. A., Echteld M. A., Penning C. \& Evenhuis H. M. (2015) Design and content validity of a new instrument to evaluate motor abilities of children with severe multiple disabilities:

Movakic (Part-I). Physical Medicine and Rehabilitation International 2, I-6.

Munde V. \& Vlaskamp C. (2015) Initiation of activities and alertness in individuals with profound intellectual and multiple disabilities. Fournal of Intellectual Disability Research 59, 284-92.

Palisano R., Rosenbaum P., Walter S., Russell D., Wood E. \& Galuppi B. (1997) Development and reliability of a system to classify gross motor function in children with cerebral palsy. Developmental Medicine and Child

Neurology 39, 214-23.

Petry, K., Maes, B. \& Vlaskamp, C. (2008). QoL-PMD. Vragenlijst over de kwaliteit van leven van personen met ernstige meervoudige beperkingen. Opbouw en handleiding. Katholieke Universiteit Leuven. Rijksuniversiteit Groningen

Petry K., Maes B. \& Vlaskamp C. (2009a) Measuring the quality of life of people with profound multiple disabilities using the QoL-PMD: first results. Research in Developmental Disabilities 30, I394-405.

Petry K., Maes B. \& Vlaskamp C. (2009b) Psychometric evaluation of a questionnaire to measure the quality of life of people with profound multiple disabilities (QoL-PMD). Research in Developmental Disabilities 30, I326-36.

Raz-Silbiger S., Lifshitz N., Katz N., Steinhart S., Cermak S. A. \& Weintraub N. (2015) Relationship between motor skills, participation in leisure activities and quality of life of children with Developmental Coordination Disorder: temporal aspects. Research in Developmental Disabilities 38, I7 I-80.

Schoenmakers M. A., Uiterwaal C. S., Gulmans V. A., Gooskens R. H. \& Helders P. J. (2005) Determinants of functional independence and quality of life in children with spina bifida. Clinical Rehabilitation 19, 677-85.

Shelly A., Davis E., Waters E., Mackinnon A., Reddihough D., Boyd R. et al. (2008) The relationship between quality of life and functioning for children with cerebral palsy. Developmental Medicine and Child Neurology 50, 199-203.

Tsoi W. S., Zhang L. A., Wang W. Y., Tsang K. L. \& Lo S. K. (2012) Improving quality of life of children with cerebral palsy: a systematic review of clinical trials. Child: Care, Health and Development 38, 2I-3I.

World Health Organization (2008) International Classification of Functioning, Disability and Health for Children and Youth. WHO, Geneva. 
S. M. Mensch et al. • Motor abilities and quality of life in children with SMD

Appendix A: Additional information about the Movakic questionnaire

Table A.I Structure of Movakic

\begin{tabular}{llll}
\hline Positions & \multicolumn{1}{c}{ Lying } & Sitting & Standing \\
\hline Situations $\rightarrow$ & I Supine & 7 Flat surface & II Without device \\
& 2 Supine with device ${ }^{\dagger}$ & 8 Dangling legs & 12 With device \\
& 3 Prone & 9 Chair/sitting device & I0 Feet on subsurface \\
& 4 Prone with device & \\
& 5 Side & \\
Grouping of motor abilities & 6 Side with device & \\
$\downarrow$ & & \\
Maintaining position & & \\
Activities & & \\
Changing body position & Items (Table A.2) with questions (Table A.3) on \\
Moving around & I Intensity manual or support by device \\
& 2 Activity of the child \\
& 3 Intensity of manual facilitation/stimulation
\end{tabular}

'Device: assistive devices such as prostheses, ortheses and specialised tools and aids for personal mobility such as canes, walkers and wheelchairs (World Health Organisation, 2008).

Table A.2 Items included in Movakic

Situations ${ }^{\dagger}$

\begin{tabular}{|c|c|c|c|c|c|c|c|c|c|c|c|c|c|}
\hline & Items & I & 2 & 3 & 4 & 5 & 6 & 7 & 8 & 9 & 10 & II & 12 \\
\hline I & Maintaining position & $x$ & & $x$ & & $x$ & & $x$ & $x$ & $x$ & $x$ & $x$ & $x$ \\
\hline 2 & Duration maintaining position & & & & & $x$ & & $x$ & $x$ & $x$ & $x$ & $x$ & $x$ \\
\hline 3 & Turning head & $x$ & $x$ & $x$ & $x$ & $x$ & $x$ & $x$ & $x$ & $x$ & $x$ & $x$ & $x$ \\
\hline 4 & Upright head & $x$ & $x$ & $x$ & $x$ & $x$ & $x$ & $x$ & $x$ & $x$ & $x$ & $x$ & $x$ \\
\hline 5 & Maintaining upright head position & $x$ & $x$ & $x$ & $x$ & & & $x$ & $x$ & $x$ & $x$ & $x$ & $x$ \\
\hline 6 & Reaching with the arms & $x$ & $x$ & $x$ & $x$ & $x$ & $x$ & $x$ & $x$ & $x$ & $x$ & $x$ & $x$ \\
\hline 7 & Take support (fore)arms & & & $x$ & $x$ & & & & & & & & \\
\hline 8 & Take support hands & & & $x$ & $x$ & & & $x$ & $x$ & & & $x$ & \\
\hline 9 & Grasping with the hands & $x$ & $x$ & $x$ & $x$ & $x$ & $x$ & $x$ & $x$ & $x$ & $x$ & $x$ & $x$ \\
\hline 10 & Roll over to the left & $x$ & & $x$ & & & & & & & & & \\
\hline II & Roll over to the right & $x$ & & $x$ & & & & & & & & & \\
\hline 12 & Roll over to prone & $x$ & & & & $x$ & & & & & & & \\
\hline 13 & Roll over to supine & & & $x$ & & $x$ & & & & & & & \\
\hline 14 & Transfer from lying to sitting & $x$ & $x$ & $x$ & & $x$ & & & & & & & \\
\hline 15 & Transfer from sitting to lying & & & & & & & $x$ & $x$ & & & & \\
\hline 16 & Transfer from sitting to standing & & & & & & & $x$ & & $x$ & $x$ & & $x$ \\
\hline 17 & Transfer from standing to sitting & & & & & & & & & $x$ & $x$ & $x$ & $x$ \\
\hline 18 & Pivoting & & & & & & & $x$ & & & & & \\
\hline 19 & Minor voluntary postural changes & & & & & & & & $x$ & $x$ & $x$ & & \\
\hline 20 & Move on & $x$ & & $x$ & & & & $x$ & & $x$ & & $x$ & $x$ \\
\hline 21 & Distance & $x$ & & $x$ & & & & $x$ & & $x$ & & $x$ & $x$ \\
\hline
\end{tabular}

${ }^{\dagger}$ Table A.I.

$\mathrm{x}$, situation containing the item.

(C) 2018 MENCAP and International Association of the Scientific Study of Intellectual and Developmental Disabilities and John Wiley \& Sons Ltd 
S. M. Mensch et al. - Motor abilities and quality of life in children with SMD

Table A.3 Examples of questions and answer categories of items on Movakic

What is the extent of manual support you gave the child to maintain this position?

\begin{tabular}{lcccc}
$\circ$ & $\circ$ & $\circ$ & $\circ$ & $\circ$ \\
Full & & & & $\begin{array}{c}\text { None } \\
\circ \\
\text { Full passive }\end{array}$ \\
$\circ$ & $\circ$ & $\circ$ & $\circ$ & $\circ$ \\
Full & $\circ$ & $\circ$ & $\circ$ & $\begin{array}{c}\circ \\
\text { full active } \\
\text { None }\end{array}$ \\
\hline
\end{tabular}

Accepted 3 August 2018

(C) 2018 MENCAP and International Association of the Scientific Study of Intellectual and Developmental Disabilities and John Wiley \& Sons Ltd 